\title{
Measuring Stability of the Cutting Process When TURNING USING TXF METALMAX SOFTWARE
}

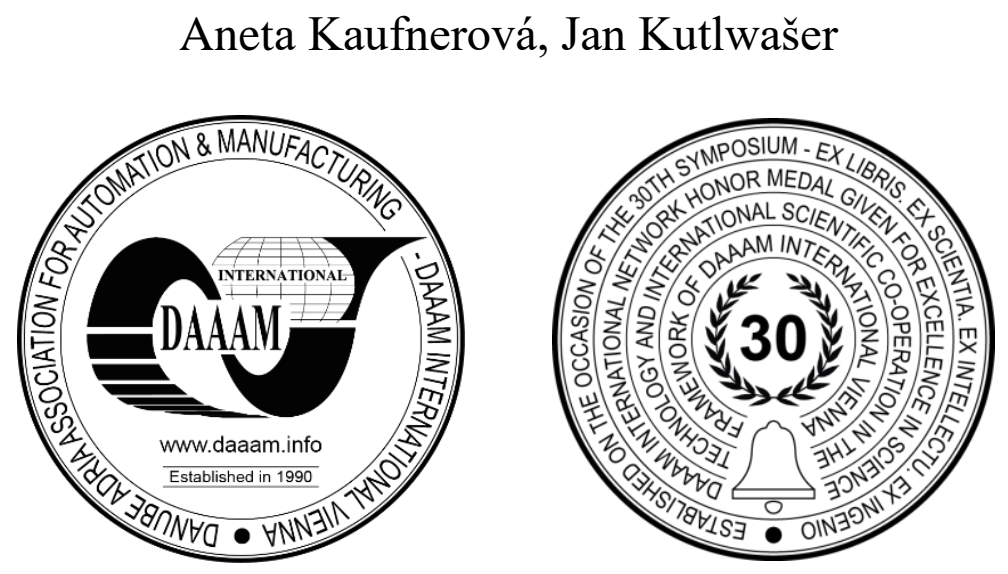

This Publication has to be referred as: Kaufnerova, A[neta] \& Kutlwaser, J[an] (2019). Measuring Stability of the Cutting Process when Turning Using TXF Metalmax Software, Proceedings of the 30th DAAAM International Symposium, pp.0982-0988, B. Katalinic (Ed.), Published by DAAAM International, ISBN 978-3-902734-22-8, ISSN 1726-9679, Vienna, Austria

DOI: $10.2507 / 30$ th.daaam.proceedings.136

\begin{abstract}
This paper deals with measuring the stability of the cutting process, namely for turning. Kistler measuring technology is used to measure stability and the results are evaluated using the TXF program from Metalmax. Part of the article is the introduction of the TXF program and description of the measuring technology. Further, we describe the problems which arose during the program analysis and experiments. These experiments were designed to explain anomalies and to find the right program settings and correct measurement of the stability of the cutting process.
\end{abstract}

Keywords: vibration; self-excited vibration; Kistler; shock hammer; accelerometer;

\section{Introduction}

Increasing productivity and reducing machining costs is an integral part of business strategy. Ways to reduce costs and increase productivity include, for example, reducing machining time, extending tool life and improving machined surface quality. The machining process is a dynamic phenomenon in which vibration occurs in most cases. These oscillations cause a deterioration of the machined surface, a reduction in tool life, increased machining time and increased machine wear. This is why measuring machine tool dynamics is in great demand today. [1], [2]

During the manufacturing process, a variety of impulses that affect the quality of the machined surfaces are generated. If these impulses are periodically repetitive, the resulting vibration is called forced vibration. This kind of vibration is widespread and many businesses are trying to minimize or best eliminate it, using various means. In this article we deal with another type of vibration that affects the cutting process: self-excited vibration.

Self-excited vibration is characterized by the fact that it does not need an external periodic excitation force to produce it. The self-excited vibration of a system is triggered by a stimulus which causes a deflection from the equilibrium position and further propagates the vibration without the application of external forces. A primary stimulus is, for example the impact of a tool on a harder structural part of the machined material. [3] 
During metal machining under certain conditions an energetic oscillation occurs, which is manifested mainly as a relative oscillation between the tool and the workpiece. The thickness of the chip varies periodically, producing a characteristic rattling sound. Regular waviness appears on the machined surface. The occurrence of self-excited vibration depends on the existence of a modulated cutting force, i.e. the existence of variable chip depths. Typically, it occurs suddenly when a certain limit value is exceeded, which is the cutting width b. [4]

The cutting process will be stable if the chip width is less than the limit width. As follows from this theorem, it is necessary to find the limit width of the chip and for this we use the stability diagram. The Faculty of Mechanical Engineering of the University of West Bohemia has measuring technology from Kistler, which is compatible with TXF software. Using this software, it is possible to generate a stability diagram from the measured data. This measuring assembly is currently used for experimental measurement of the stability of the turning process.

The main aim of this research was to find out how TXF Metalmax software works on the basis of analysis. Further, verify the results of the analysis by experiment. In this paper we present the use of TXF software with the measuring technology and the pitfalls in measuring the stability of the cutting process.

\section{Description of the equipment}

TXF is part of the METALMAX package, which also includes MilSim, PCScope and Harmonizer. It is specialized frequency analysis software, which is adapted for fast measurement of machine tool dynamics. The primary function of this program is to collect data from two sensors, an accelerometer and a shock hammer, to record the frequency response. Subsequently, the data is used to create a graphical representation of the measured results in the form of a stability diagram. [5]

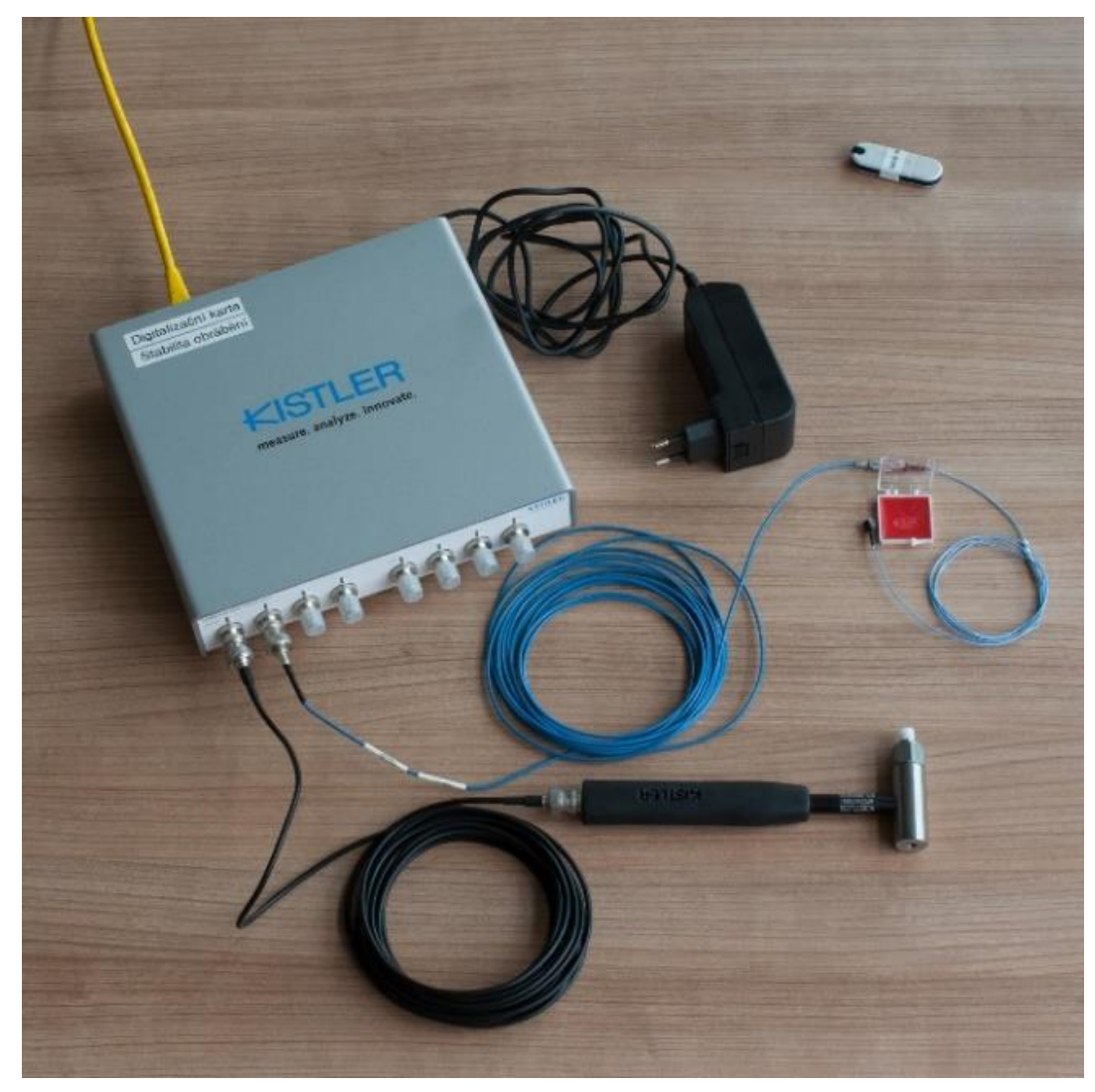

Fig. 1. Measuring equipment

TXF is primarily designed to measure the stability of a milling cutting process. But TXF also offers other cutting modules such as turning and drilling. The TXF software was created and based on a study by Professor Jiri Tlusty. [3]

In the course Practical Experimental Machining Methods, which is taught at the Department of Machining Technology, there is a task to measure the stability of the cutting process on an Emco Maxxturn 25 lathe. During the analysis of the TXF software various bugs were ironed out and explained. Individual experiments are described in the next section.

2.1. First experiment 
The first experiment dealt with the influence of individual workpieces on the resulting stability diagram. The experiment was carried out on a cylindrical blank with a diameter of $10.3 \mathrm{~mm}$ and a length of $150 \mathrm{~mm}$. The cylindrical workpiece was made from 42CrMo4 and we used a cutting tool from Iscar SCLCL 1212F-09 with a CCMT insert 09T304SM. The experiment was done on an Emco Maxxturn 25 turning centre.

The measuring axes corresponded to the turning coordinate system. It was measured in the X, Y and XY axes. Two types of graphs were generated from the recorded values.

- Real Relative Frequency Response

- Stability Diagram

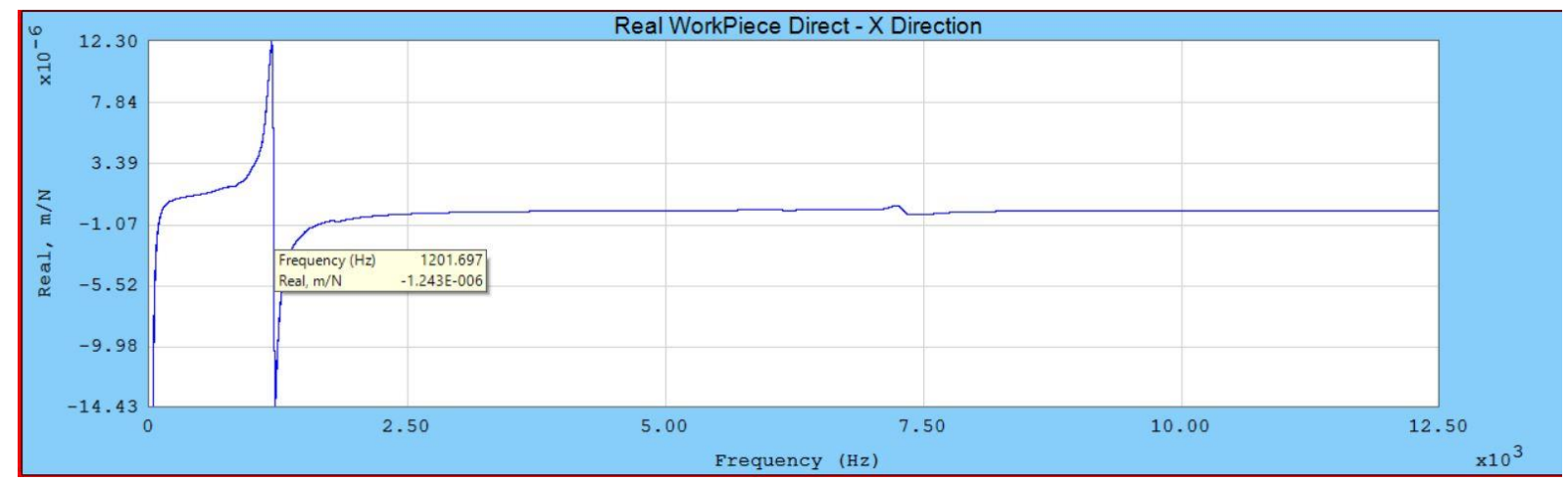

Fig. 2. Real Relative Frequency Response - direct X

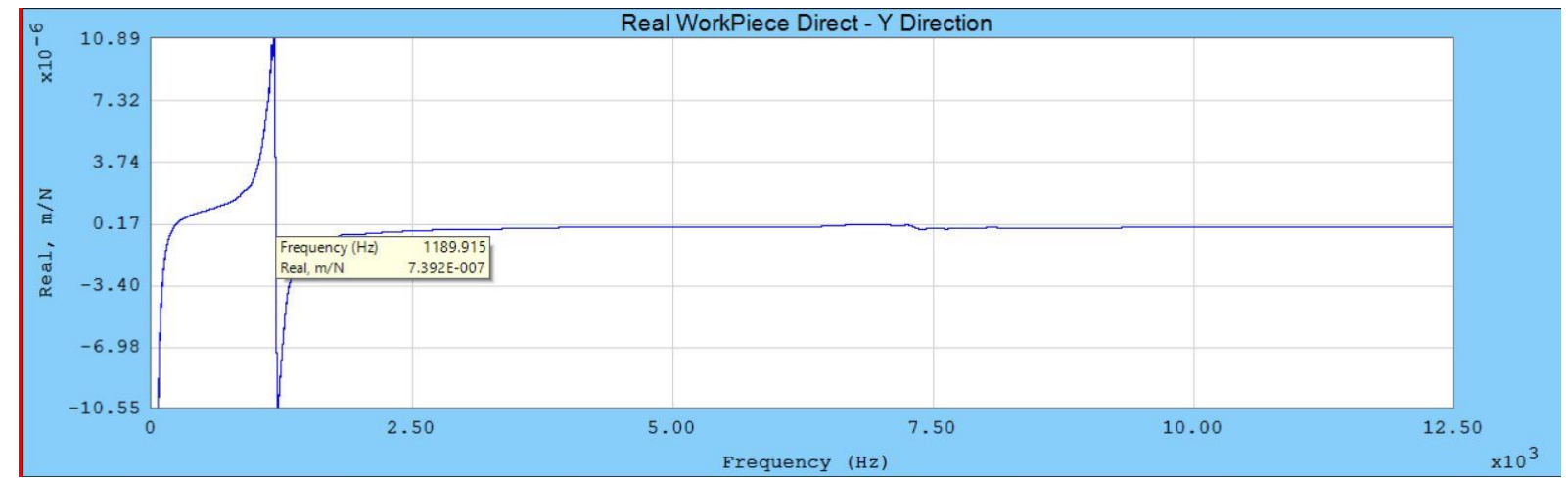

Fig. 3. Real Relative Frequency Response - direct Y

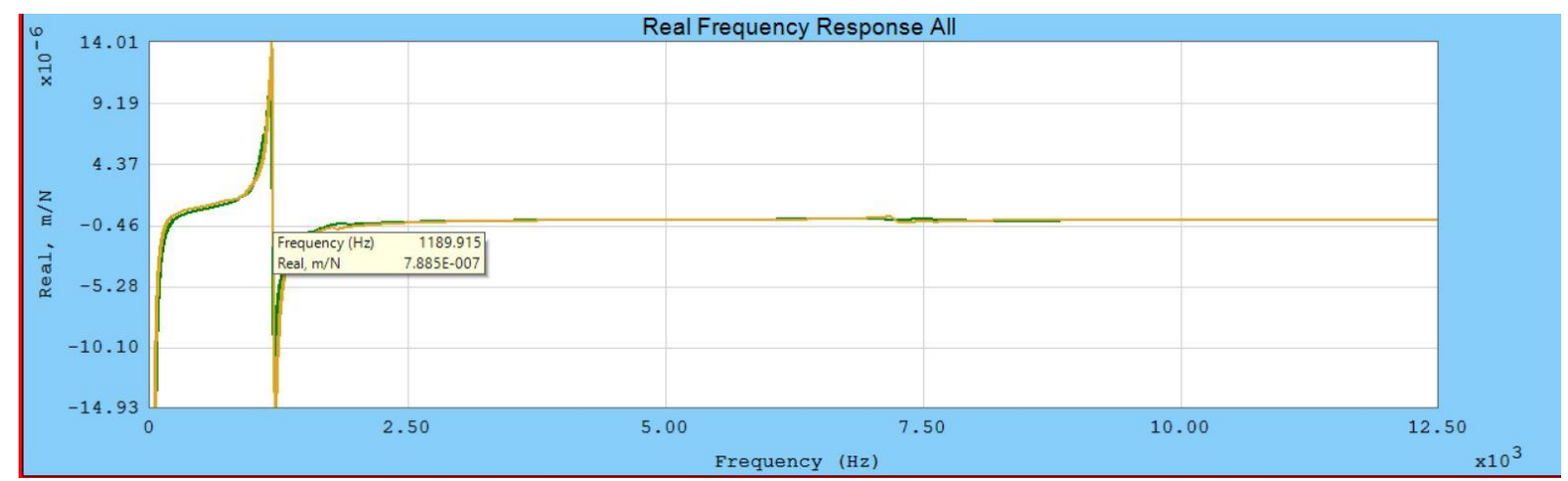

Fig. 4. Real Relative Frequency Response - direct XY

The graphs were used to determine whether the measurement in the individual axes affects the natural frequency of the workpiece. The natural frequency in all measurements was around $1200[\mathrm{~Hz}]$ and it follows that the natural frequency was not affected by the measurement axis. The curves of the individual measurements differed only slightly. 


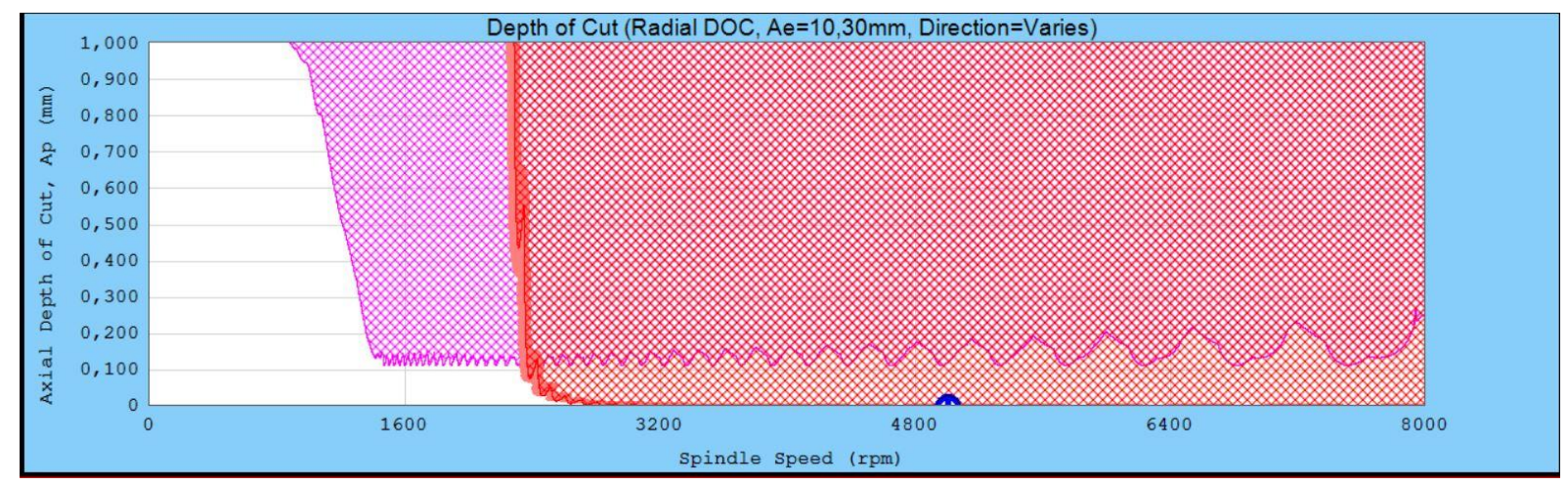

Fig. 5. Stability Diagram- direct $X$

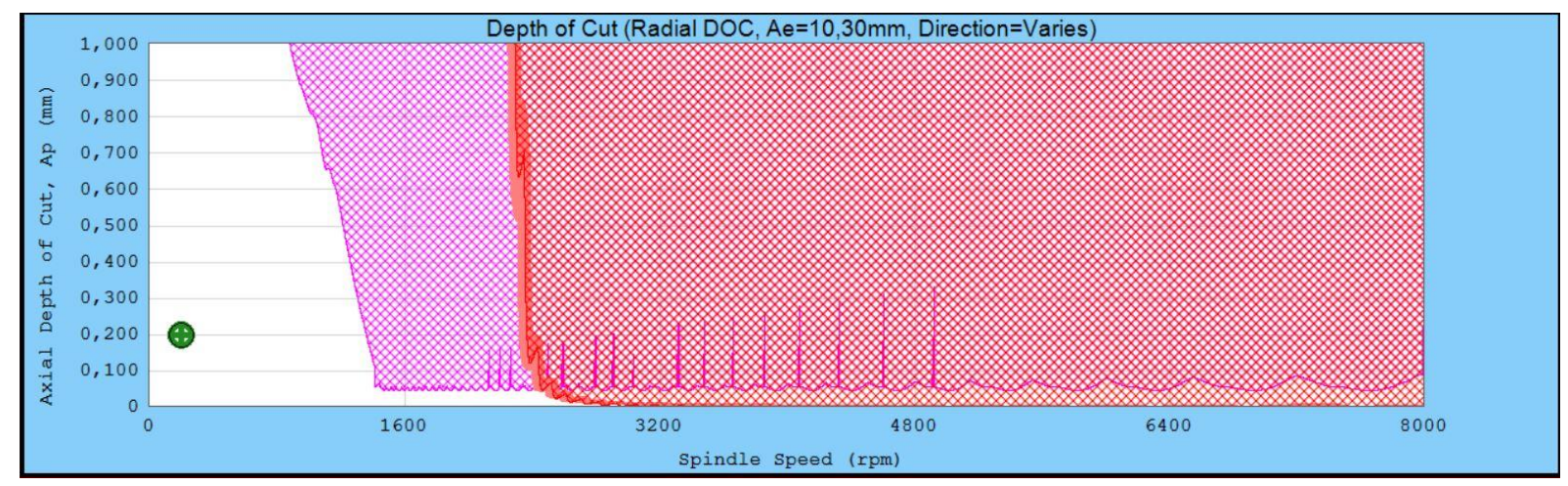

Fig. 6. Stability Diagram- direct Y

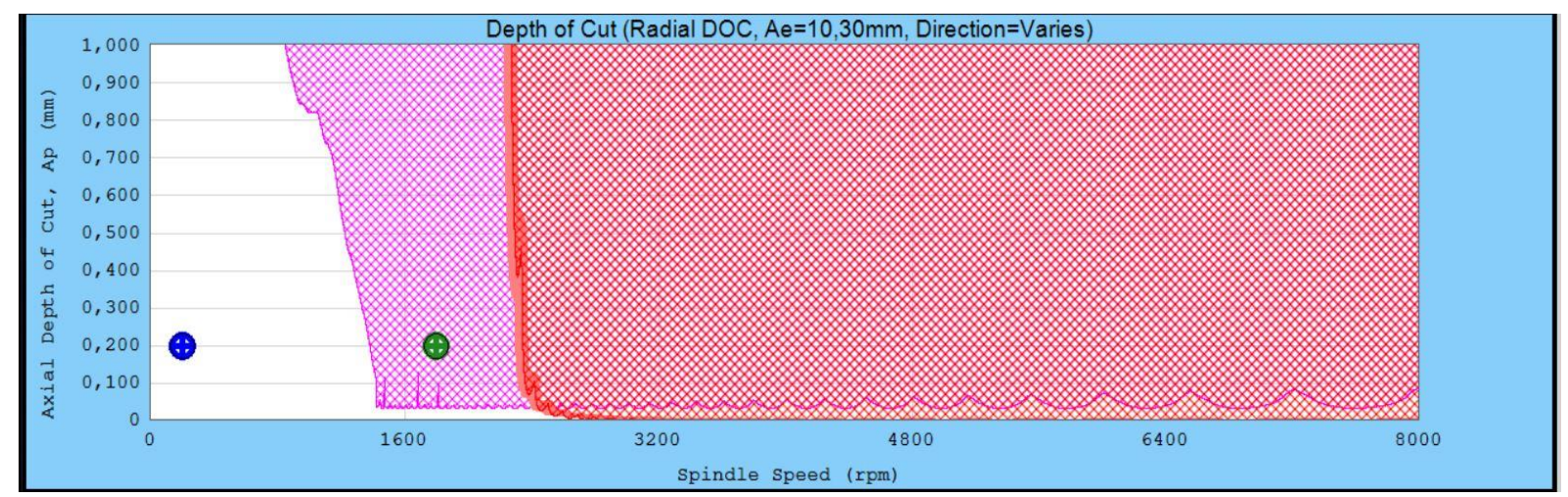

Fig. 7. Stability Diagram- direct XY

From the previous graphs, as already mentioned, it was seen that the natural frequency of the system was around $1200[\mathrm{~Hz}]$. Therefore, the stability diagrams are almost identical in the individual axes. The difference between the diagrams was more pronounced in the shift in the violet area (vibration induced by the cutting force) downwards.

The next step was to determine the cutting conditions from the stability diagram. The diagrams show that when machining a workpiece with a cutting depth of $0.45[\mathrm{~mm}]$, stable machining will be performed up to 1100 [rpm]. From practical experience, the machining should calm down at 200-300 [rpm].

The analysis of the diagrams shows that the stability diagrams are erroneous and this has led to a search to find out why. First, the parameters were changed and their effect on the stability diagram was examined. During the previous analysis, it was found that the parameter 'Cutting Diameter' in the turning process is the diameter of the workpiece. This parameter can greatly affect the measurement results, so it is important to enter it correctly. Tool and material parameters have the most significant influence on changes to the stability diagram. Rapid changes to the diagram can occur by incorrectly setting the number of tool blades. A more significant change is caused by the wavelength, which is affected by both the back angle and the wear. [6] 


\subsection{Second experiment}

The second experiment deals with the measurement of an object with different hammer tips and their influence on the frequency response function. This experiment is based on rules from Metalmax.

Choosing a hammer and an accelerometer is basically an intuitive decision. The hammer from Kistler comes with four tips. Each tip has a different hardness, shock duration and frequency response. The hardness of the hammer tip affects the frequency response but has little effect on the magnitude of the force.

Three types of terminals were selected for the experiment:

- $\quad$ Green tip (Hard) 9908

- $\quad$ Red tip (Medium) 9910

- White tip (Soft) 9906

Two measurements were made for each type of tip. Measurements were taken along the $\mathrm{X}$ axis. Coherence plots were then generated from the recorded values.

The hammer blow quality is evaluated by coherence. Coherence is used in multichannel measurements to determine the effect of a signal on another and thus represents a measure of the dependence of one signal on another. The dependence of the two signals increases, the higher the coherence value. When coherence decreases, this means that the response is also dependent on a different type of signal than the excitation. For example, the output signal may be affected by noise (due to under-excitation) or another type of signal. [7]

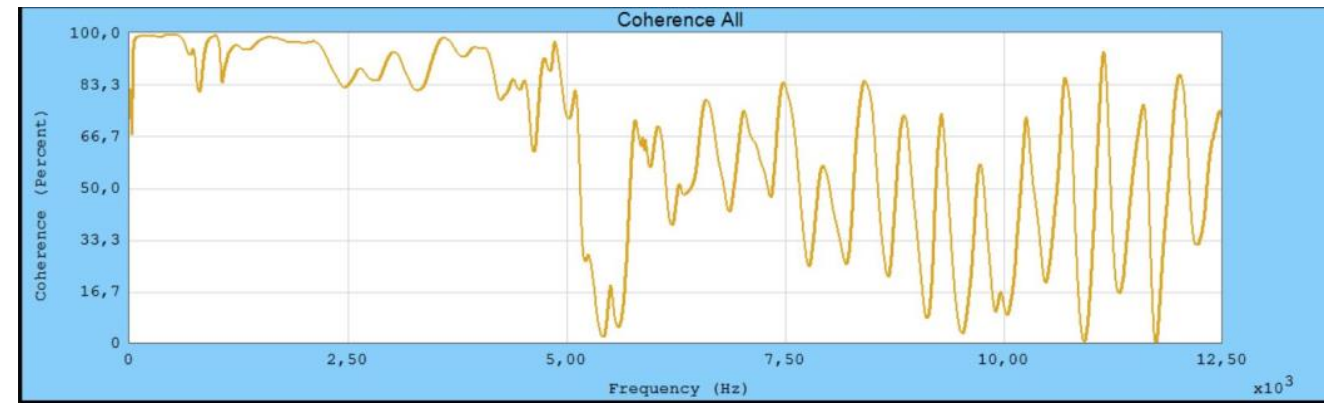

Fig. 8. Coherence plot - green tip

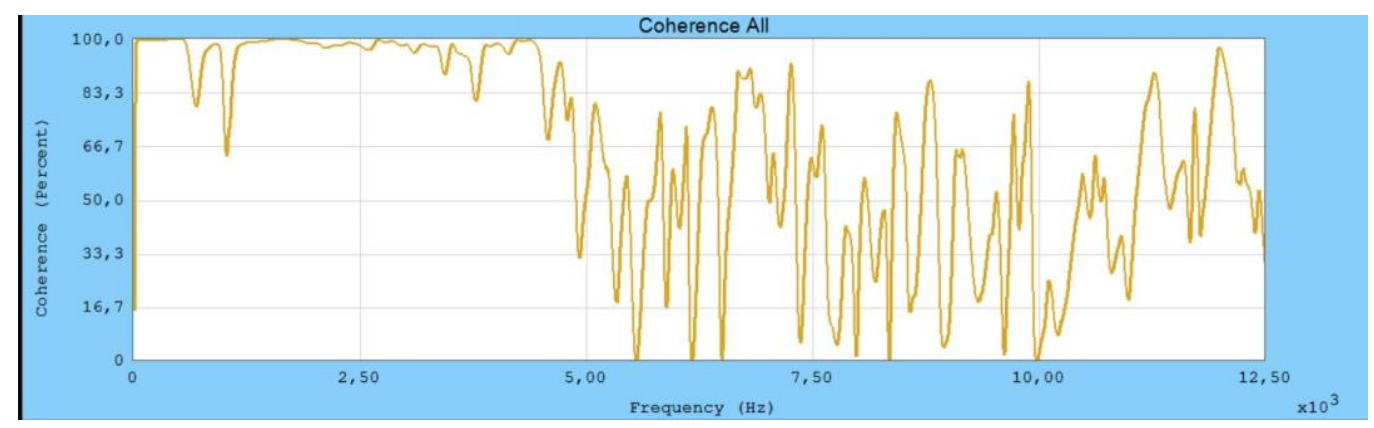

Fig. 9. Coherence plot - red tip

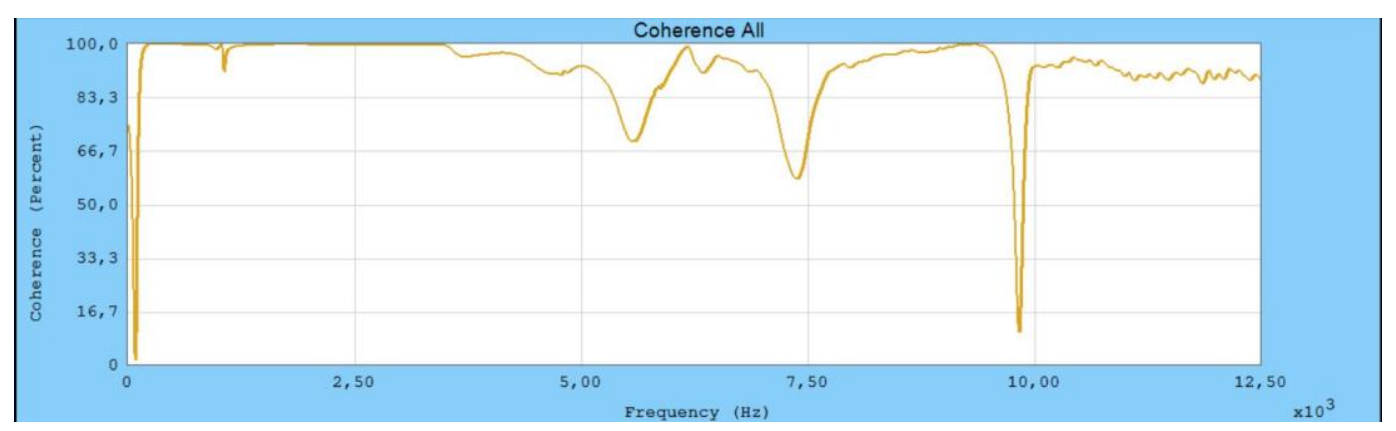

Fig. 10. Coherence plot- white tip 
From the individual measurements and assessment of the quality of the measured data, it was found that the white tip was the best option. The output signal when measuring the green and red terminals most likely had insufficient excitation of the object.

In the second experiment the correct choice of the white tip for measurement was confirmed. Even in this experiment the cause of the stability diagram error was not found and was therefore sought in another area of the software.

\subsection{Thirds experiment}

In this part of the experiment we investigated whether the measured natural frequency of the system corresponds to the real value. A tuning fork with a natural frequency of $440[\mathrm{~Hz}]$ was used for this purpose.

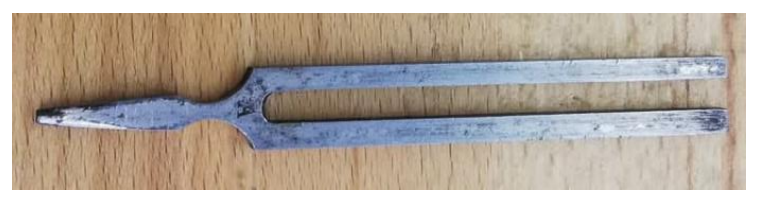

Fig. 11. A - $440[\mathrm{~Hz}]$ Tuning fork

Two measurements were taken in the experiment. The resulting graphs are shown below.

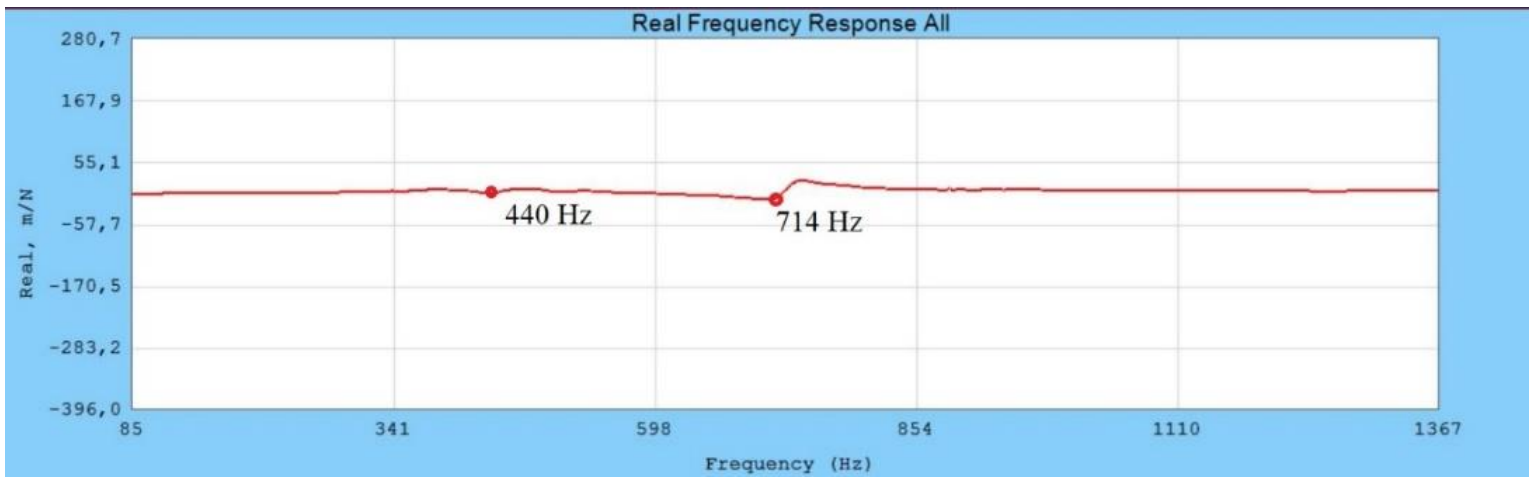

Fig. 12. Real Frequency Response - measurement 1

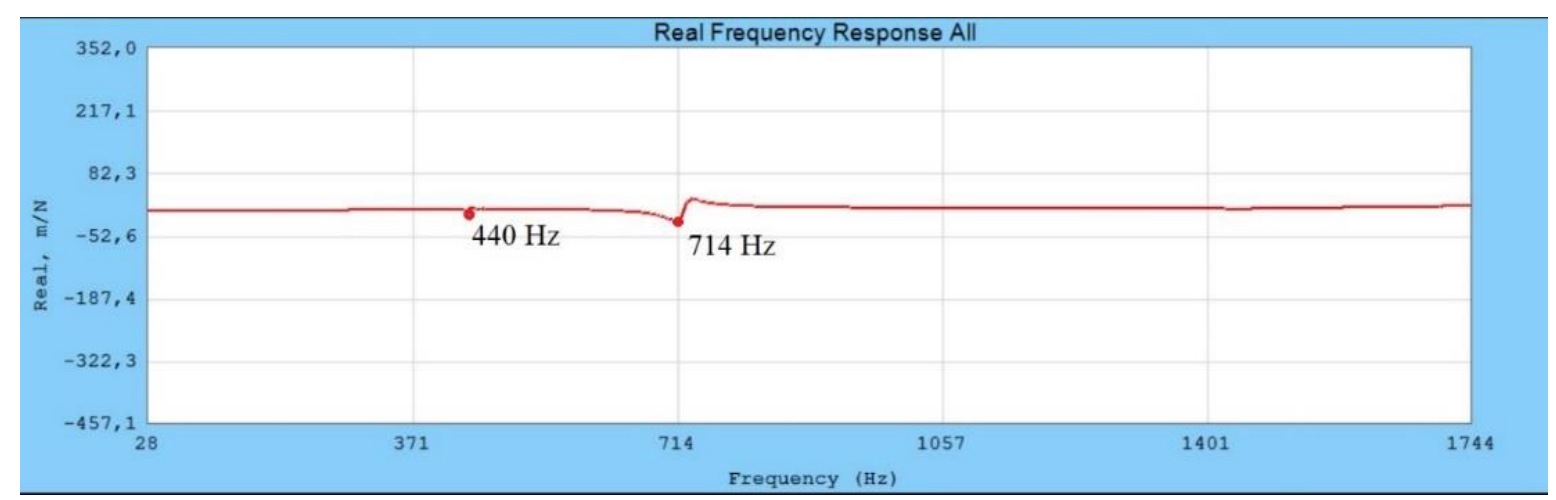

Fig. 13. Real Frequency Response - measurement 2

The natural frequency of the tuning fork according to the measurement should be $714[\mathrm{~Hz}]$. The real natural frequency value was displayed as a slight curve depression $(440[\mathrm{~Hz}])$. The last part of the experiment did not produce satisfactory results. These results led to the assumption that the sampling frequency against the bandwidth was not wrong.

The Nyquist-Shannon theorem states that a continuous signal can be reconstructed from a series of discrete samples only if the sampling frequency is at least twice the maximum frequency of the input signal. This led us to check the sampling frequency. [8] 


\begin{tabular}{|c|c|c|}
\hline $\begin{array}{c}\text { Sampling } \\
\text { frequency [Hz] }\end{array}$ & $\begin{array}{c}\text { Measurement } \\
\text { Bandwidth [Hz] }\end{array}$ & / \\
\hline 2500 & 1000 & 2.5 \\
\hline 6250 & 2000 & 3.125 \\
\hline 12500 & 5000 & 2.5 \\
\hline 25000 & 10000 & 2.5 \\
\hline 50000 & 20000 & 2.5 \\
\hline 62500 & 20000 & 3.125 \\
\hline
\end{tabular}

Table 1. Verification Nyquist-Shannon theorem

The resulting values in the table correspond to the Nyquist-Shannon theorem. In the last part of the experiment it was found that the measured input signal probably does not match the real signal.

\section{Conclusion}

The main aim of this research was to find out how TXF Metalmax software works on the basis of analysis. Further, verify the results of the analysis by experiment. A summary of the analysis and verification results is described below.

In the first experiment, the measurement of the frequency response function was performed on a $42 \mathrm{CrMo} 4$ workpiece. Stability diagrams were then generated using the TXF program. The analysis of stability charts revealed that the resulting stability charts are not correct. Part of the first measurement was to find an error in the program settings and the influence of individual parameters on the stability diagram. In the first measurement, no errors or parameters were found that would cause incorrect diagrams. This led to further questions, which resulted in further experiments.

In the second experiment, measurements were made to determine the effect of the hammer tips on the resulting frequency response function. The result of the experiment was to confirm the correct choice of the impact hammer tip for the first measurement.

In the last experiment, the frequency response function of a tuning fork with a natural frequency of $440 \mathrm{~Hz}$ was measured. The natural frequency values did not correspond to reality.

In conclusion, the values evaluated during the experiments did not meet the theoretical assumptions. One of the expected consequences could be the wrong configuration between the Kistler measuring assembly and the TXF program. Another possible cause of poor program measurement is disregarding the main cutting angle when calculating vibrations caused by the cutting force. Other possible causes may be the rigidity of the workpiece clamping and the unsure mounting of the accelerometer on the measured object. Further time-consuming experiments would be needed to verify these possibilities.

\section{Acknowledgments}

The article has been prepared in the project LO1502 'Development of the Regional Technological Institute' under the auspices of the National Sustainability Programme I of the Ministry of Education of the Czech Republic aimed to support research, experimental development and innovation.

\section{References}

[1] Hadraba, P.; Hadas., Z. (2019). Time-domain regenerative chatter analysis of non-linear stiffness system. Scopus, Vol. 1044 (September 2019), page numbers (3-10), ISSN 21945357

[2] Kumar, (2017). Review on Optimization Techniques used for Determining Machining Conditions to get Effective Tool Life and Surface Finish, Proceedings of the 28th DAAAM International Symposium, ISSN 1726-9687, ISBN 978-3-902734-12-9, Katalinic, B. (Ed.), pp. 235-264, Published by DAAAM International, Vienna, DOI 10.2507/daaam.scibook.2017.19

[3] Tlustý, J.; Špaček, L. (1953). Samobuzené kmity v obráběcích strojích, Československá akademie věd, Praha

[4] Fojtů, P. (2009). Problematika samobuzeného kmitání při obrábění, ČVUT, Praha,

[5] Metalmax.(2011). TXF Users Manual, unpublished

[6] Tyler, Ch.; Schmitz, T. (2014). Process Damping Milling Model Database, Available from: https://www.researchgate.net/publication/288160550_Process_damping_milling_model_database

[7] Gao, Z.; Lin, J.; Wang, X.; Liao, Y. (2019). Time-domain regenerative chatter analysis of non-linear stiffness system. Scopus, Vol. 1044 (September 2019), page numbers (3-10), ISSN 21945357

[8] Schmalenstroeer, J.; Haeb-Umbacg, R. (2018). Efficient sampling rate offset compensation - An overlap-save based approach. Scopus, Vol. 2018(November 2018), page number (499-503), ISSN 221954 